\title{
A OCORRÊNCIA DE VOÇOROCAS EM GOUVEIA, MG: CARACTERÍSTICAS E PROCESSOS ASSOCIADOS
}

\author{
Cristina Helena Ribeiro Rocha Augustin ${ }^{1}$ \& Paulo Roberto Antunes Aranha ${ }^{1}$
}

\begin{abstract}
This article presents a synthesis of a research conducted in the region of Gouveia since 1984. Theses studies have consolidated an important overview of the geomorphology of the area, with emphasis on the dynamic processes of the landscape, specially gullying. The erosional forms generated by these processes are distinguished features on slopes, causing agricultural and cattle grazing problems for farmers, due to the quantity of eroded soil as well as the size of the gully form, with negative impact on the economy of the region. The evolution of gullies is linked to the development of channels opened by the erosion of concentrated runoff or by the collapse of the roof of tubular voids formed by piping. When factors internal or external to the channel break the dynamic equilibrium between the erosive power of the water running inside the channel and the quantity of remobilised soil, the enlargement of the walls as well as headward evolution of the initial down cutting occurs originating gullies. This development occurs through the combined effect of linear and basal erosion, piping and mass movements in the walls, such as landslides, mudflow and fall of weathered rock. Gullying occurs predominantly in the deeply weathered material and soil from more cohesive rock. Most of the studied gullies present springs and outlets with running water during almost the whole year. They are connected to a main drainage channel, so that they can be considered part of the drainage network of the area. Observations show that most of the gullies have been induced by human activities, but some of them developed over palaeo-channels opened as old as the Pleistocene, showing a poly-cyclic evolution.
\end{abstract}

Keywords: gully, piping, soil erosion

\section{RESUMO}

\begin{abstract}
Trata-se de artigo que apresenta uma síntese dos resultados de vários anos de estudo de voçorocas da região de Gouveia. Essas pesquisas tiveram início em 1984 e produziram um conhecimento importante sobre a geomorfologia da área, com ênfase nos processos dinâmicos da paisagem, em especial os voçorocamentos. As formas erosivas geradas por eles estão presentes de uma maneira marcante no relevo, tornando-se, em algumas bacias, um problema para as atividades agro-pecuárias em razão da grande quantidade de material retirado dos canais e da largura, comprimento e profundidade dos mesmos. Evoluem a partir da abertura de canais superficiais pela água concentrada de chuva, ou formados pelo colapso do teto de dutos criados por piping. A voçoroca se instala, no entanto, quando fatores internos, ou externos, ao canal, desestabilizam o equilíbrio dinâmico entre a quantidade de água que passa no canal e a quantidade de sedimentos remobilizados e transportados dentro dele. Contribuem para que esse desequilíbrio ocorra, além da erosão em especial a basal, os processos de transferência gravitacional e o piping que se instalam nas paredes do canal. $\mathrm{O}$ voçorocamento ocorre predominantemente em rochas mais coesas, nas quais corta um profundo manto de intemperismo. Quase todas as voçorocas estudadas apresentam fluxo de água, pelo menos durante parte do ano e estão conectadas a um córrego, ribeirão ou rio, fazendo parte, portanto, da rede de drenagem. Observações realizadas na área indicam que a maior parte das voçorocas foi iniciada em decorrência das atividades antrópicas, entre os quais o desmatamento e as queimadas periódicas a que a área é submetida, o pisoteio do gado, a presença de trilhas, a drenagem das estradas vicinais, a abertura de valas e uso de tipo específico de cerca com murunduns, são as mais importantes. No entanto, foram identificadas outras, de caráter poli-cíclico, que se desenvolveram em páleo-canais de voçorocas pretéritas, datadas desde o Pleistoceno.
\end{abstract}

Palavras-Chave: voçoroca, erosão superficial, erosão subsuperficial, voçorocamento.

\section{INTRODUÇÃO}

A importância do voçorocamento como processo erosivo, e das voçorocas como forma da ação desse tipo de erosão, em várias regiões da terra, pode ser aferida pelo aumento do número de publicações sobre o tema a partir da década de 70 e, em especial, a partir da de 80 (Ireland et al. 1939, Petit \& Bourgeat 1966, Rougerie 1966, Heede 1967, Jones 1971, Young 1972, Tricart 1966, 1973, Kirkby 1978, Hudson 1985, Crouch \& Blong 1989, Crouch 1990, Moeyersons 1991, Bocco 1991, Bull \& Kirkby 1997, Poesen \& Govers 1990, Poesen 1993, 
Poesen et al. 1998, Valentin et al. 2005, Casali et al. 2006).

No Brasil, as primeiras publicações específicas aparecem a partir da década de 50 (Pichler 1953) e os estudos mais sistematizados, a partir da década de 70, por Fiori \& Soares (1976) e Furlani (1980), entre outros, muito embora a temática já tivesse aparecido em publicações da Revista Brasileira de Geografia, na década de 60, reportando a ocorrência dessas formas erosivas por autores franceses em Madagascar (Petit et al. 1964, Rougerie 1966). No final da década de 60 e durante a seguinte, os trabalhos sobre o tema apresentavam abordagens predominantemente morfológicas, como por exemplo, o de Vieira (1978) e Bigarella \& Mazuchowski (1985), que associavam o fenômeno à ação conjunta das águas superficiais e subsuperficiais; geotécnica, com destaque para as publicações dos pesquisadores do Instituto Nacional de Pesquisas (INPE), entre eles Iwasa \& Prandini (1980), além das produzidas por pesquisadores da Escola de Engenharia de São Carlos, como Rodrigues \& Vilar 1984 a,b. Essas pesquisas tiveram o mérito de chamar a atenção sobre a forma voçoroca e também sobre a dinâmica do processo.

Em meados da década de 80 tem início no Instituto de Geociências (IGC) da UFMG, o desenvolvimento de pesquisas (Augustin \& Saadi, 1985, Malheiros 1985, Ferreira 1985, Alvarenga 1985) sobre a temática, bem como na UFRJ (Coelho Neto et al. 1988, Oliveira 1989). Os trabalhos apresentados a partir de meados dessa década marcam o predomínio da grafia voçoroca sobre a utilizada por alguns autores, principalmente paulistas: vossoroca e boçoroca. A utilização dessa última, possivelmente, teve sua origem na publicação de Pichler (1953:p.3), um dos primeiros estudos sistemático sobre o tema, no qual ele se reporta a Teodoro Sampaio (18851937), para quem o significado etimológico da palavra boçoroca corresponderia a "ibi-çoroc", do tupi-guarani, que significa "terra rasgada ou rasgão do solo".

Essa extensa bibliografia, tanto no Brasil, como internacionalmente, indica a amplitude da ocorrência do problema, e a necessidade de se conhecer melhor o problema, como meio de contê-lo.

Em Gouveia, MG, os voçorocamentos vêm sendo estudados há vários anos, possibilitando a compreensão de alguns mecanismos associados ao processo, a iniciação e ao desenvolvimento das voçorocas. O estudo produziu um extenso conjunto de dados sobre a área e permitiu que se aprofundasse o conhecimento sobre a forma erosiva em si, o meio biofísico na qual ocorre, e sobre os processos erosivos a ela associados.

Como as voçorocas são comuns a outras áreas no Brasil e a outros contextos climáticos, litológicos, geomorfológicos e também sócio-econômicos, tornase importante a apresentação e a discussão de alguns aspectos relativos aos dados obtidos em Gouveia, como base comparativa em relação à ocorrência desses processos em outras áreas. Neste sentido, o objetivo do presente trabalho é o de apresentar resultados obtidos pelos estudos conduzidos na área, inclusive como contribuição para uma definição mais clara tanto do processo, quanto da forma.

\section{CARACTERÍSTICASDA ÁREADE ESTUDO}

Gouveia localiza-se no Estado de Minas Gerais, na Serra do Espinhaço, um cinturão orogênico do PréCambriano, que se estende por mais de $1.000 \mathrm{Km}$, de Minas Gerais até o Estado da Bahia. Localmente, o Espinhaço Meridional, é formado por quartzitos do supergrupo Espinhaço e por xistos, do supergrupo Rio Paraúna. Estas rochas são cortadas por rochas intrusivas básicas e metabásicas (figura 1).

Topograficamente, os quartzitos e os xistos encontram-se em posições mais elevadas em razão das deformações e soerguimentos tectônicos a que foram submetidos no Pré-Cambriano, sendo que a erosão diferencial não foi capaz de inverter esse quadro. A erosão atuou predominantemente ao longo dos eixos dos anticlinais, retirando as camadas dos quartzitos e xistos, provocando a exumação do embasamento cristalino granito-gnaíssico na porção central do município. O resultado foi a elaboração de um relevo levemente escalonado, com as maiores altitudes ocorrendo nos quartzitos (acima de $1.200 \mathrm{~m}$ ), depois nos xistos $(1.100-1.200 \mathrm{~m})$ e finalmente no complexo granítico, mais baixos $(900-1.100 \mathrm{~m})$ caracterizando uma depressão (figura 2).

Nela, encontram-se encaixados os canais fluviais dos dois maiores cursos de água do município: ribeirões da Areia e do Chiqueiro, afluentes do rio Paraúna, nível de base local e limite sul do município de Gouveia (Augustin 1995).

Na Depressão de Gouveia desenvolveu-se uma seqüência de colinas convexas e policonvexas, de topos achatados e largos, que funcionam como divisores de água entre várias pequenas bacias de drenagem. Essas colinas encontram-se bastante dissecadas pela erosão fluvial, com voçorocamento acentuado (Augustin 1995, Augustin et al. 1999, Valadão 1986). São recobertas por um espesso manto de alteração proveniente da decomposição de granitos-gnaisses, xistos, milonitos, rochas básicas e metabásicas. A cobertura vegetal predominante na Depressão é o Cerrado, em graus variados de degradação, desde o cerrado propriamente dito, até o campo sujo. Ao longo dos cursos de água ocorrem matas galerias.

O clima é o tropical sub-úmido, com média anual de precipitação em torno de $1.500 \mathrm{~mm}$, concentrados entre os meses de outubro a março, período com as temperaturas médias mais elevadas, em torno de $21^{\circ} \mathrm{C}$. $\mathrm{O}$ inverno é frio e seco, com médias anuais de $18^{\circ} \mathrm{C}$, prolongando-se de abril a setembro (Augustin 1995).

Os principais tipos de solo na área de ocorrência das voçorocas são: os latossolos vermelho-amarelos, desenvolvidos sobre os granito-gnaisses, xistos, micaxistos e milonitos; os latossolos vermelho-escuros, 


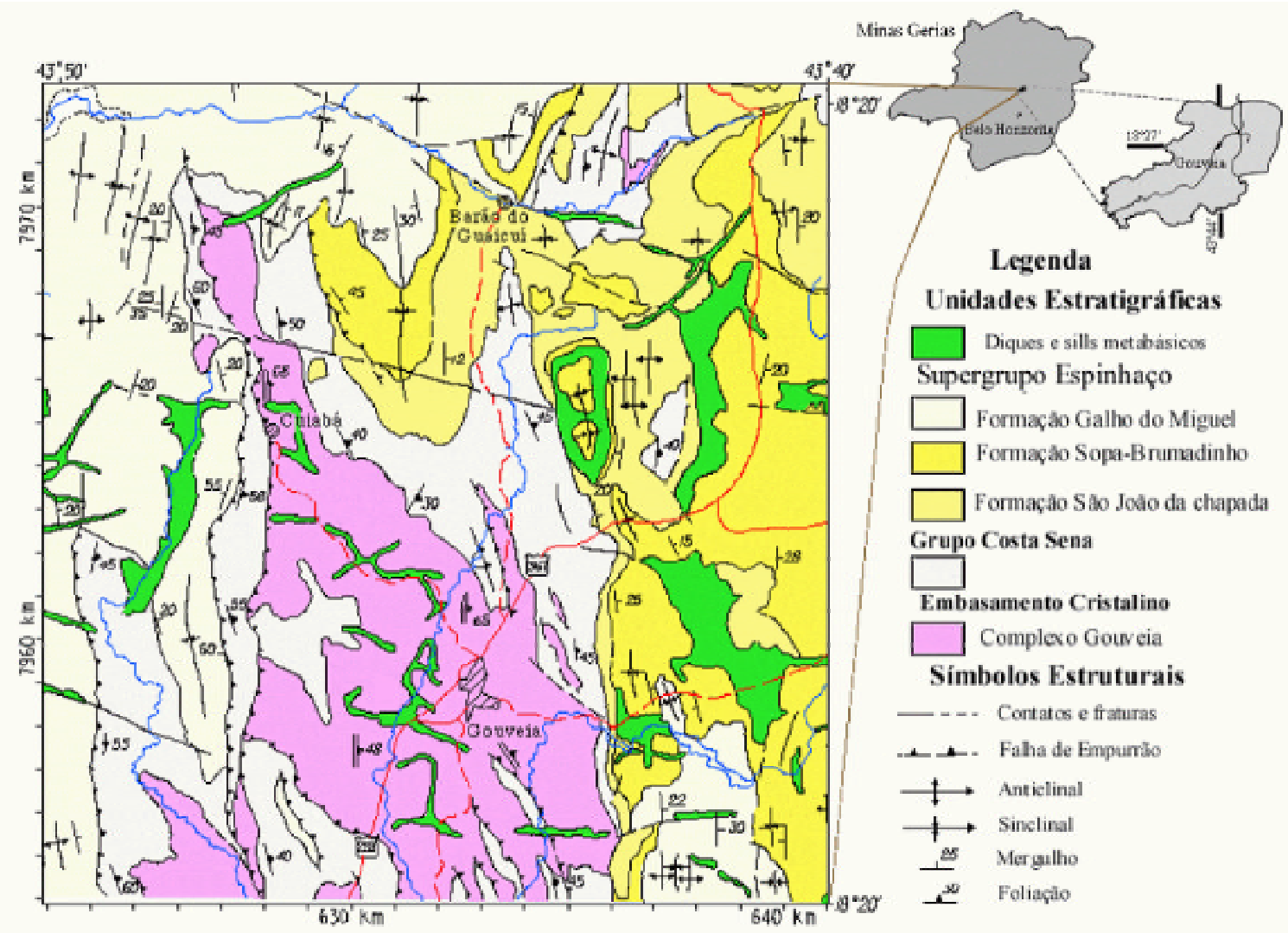

Figura 1- Mapa geológico e de localização da área de estudo.

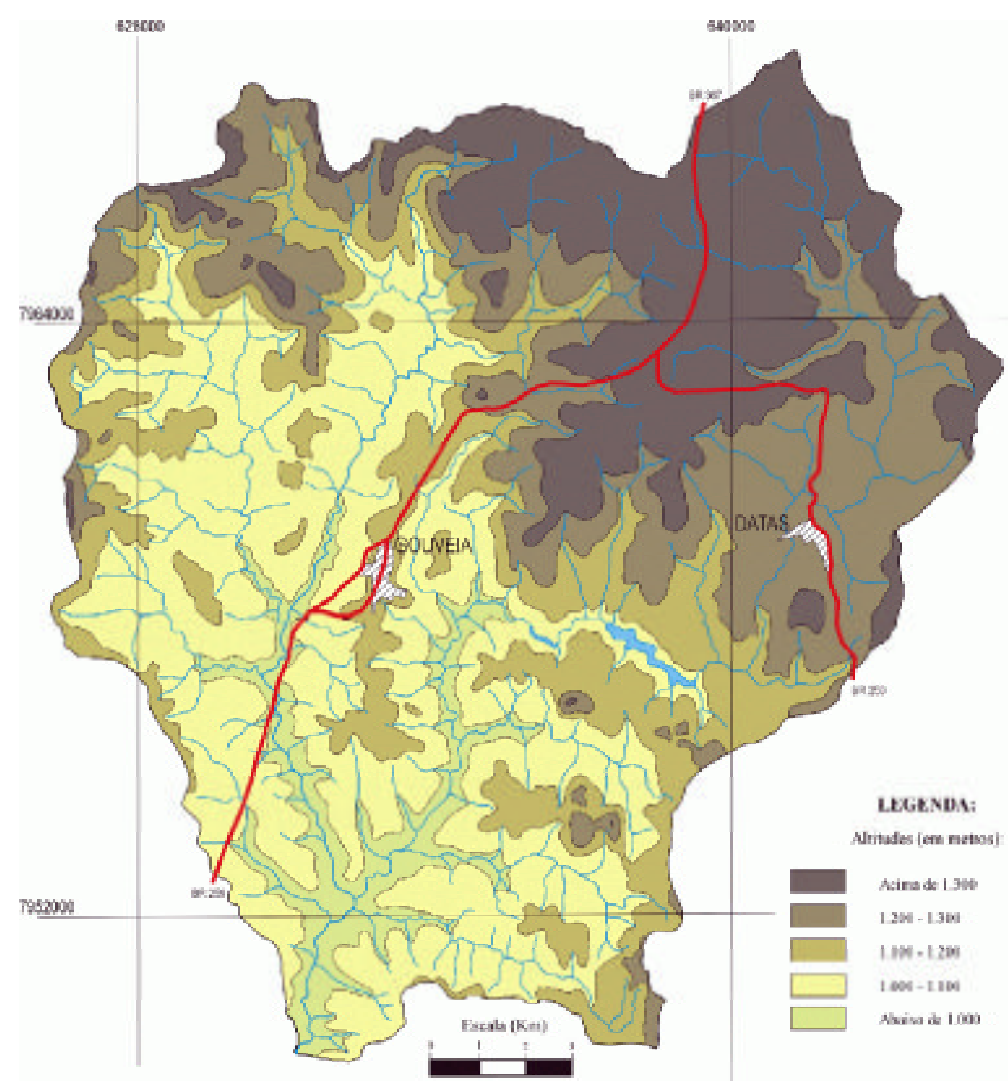

Figura 2- Mapa dos níveis topográficos da região de Gouveia-MG. 
provenientes da decomposição das rochas básicas e metabásicas e os cambissolos, encontrados tanto sobre os granito-gnaisses, milonitos, quanto sobre os xistos (Augustin 1995, Diniz 2002).

\section{AS VOÇOROCAS DA REGIÃO DE GOUVEIA}

Neste trabalho são discutidos e apresentados os resultados do estudo de 28 voçorocas, localizadas à montante das bacias dos ribeirões da Areia e do Chiqueiro, embora, somente na bacia do ribeirão do Chiqueiro, tenham sido mapeadas cerca de 320 dessas predominantemente, no domínio dessas rochas ocorre material coesivo fino que favorece um maior escoamento superficial de água de chuva.

No domínio dos quartzitos do supergrupo Espinhaço, o intenso fraturamento das rochas, associado à ocorrência de material pouco ou não coesivo resultante da alteração do quartzito, facilita a dispersão da água de escoamento superficial e o aumento na taxa de infiltração. Ocasionalmente, contudo, em locais com alteração química do filito, filito ferruginoso, rochas intrusivas ou mesmo em páleodepressões, preenchidas pelo material coluvial fino silto-

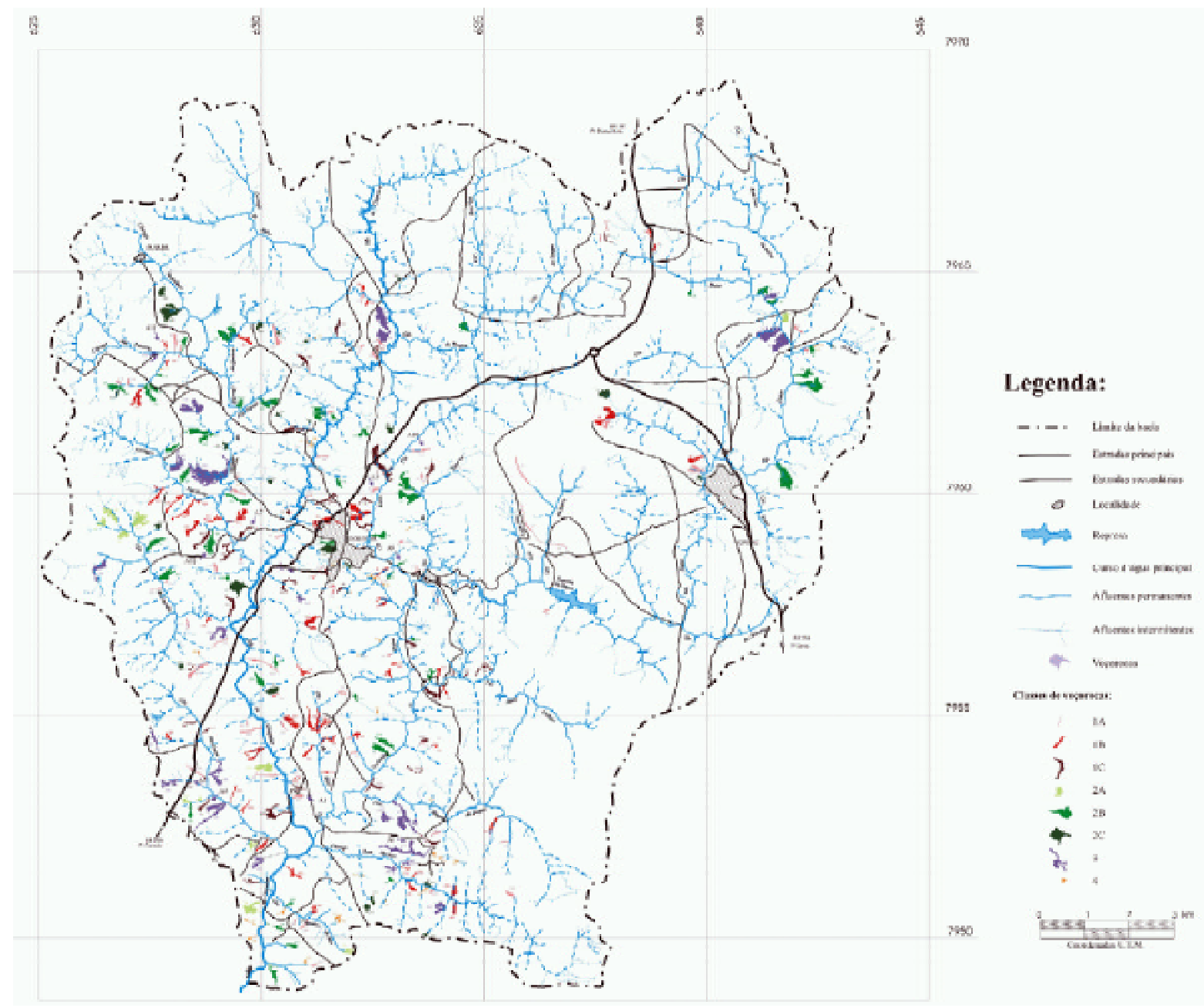

Figura 3- Mapa da rede de drenagem e localização das voçorocas da bacia do córrego do Chiqueiro, Gouveia, MG.

formas erosivas (figura 3).

A distribuição das voçorocas pode ser considerada bastante uniforme na área dessas duas bacias na porção restrita à depressão de Gouveia (Augustin 1995, Aranha 2002).

Condicionantes Geológico e Geomorfológicos

A presença das voçorocas, no município, está concentrada nas áreas com substrato rochoso formado por granito-gnaisses do embasamento, xistos do Supergrupo Paraúna ou por milonitos e rochas básicas e metabásicas. Isto está relacionado ao fato de que, arenoso, proveniente da decomposição de formações da base do Espinhaço, é possível detectar a presença de voçorocas, mesmo se tratando de domínio das rochas quartzíticas.

As voçorocas, sem exceção, cortam verticalmente o manto alterado (figuras 4 e 5 ).

Essa intensa atividade de entalhe gera o aparecimento de paredes com alturas que variam de 3 a $30 \mathrm{~m}$, quase sempre abruptas, como descritas na literatura em geral. O manto alterado é formado por 4 tipos de combinações do saprolito com o solo pedológico: a. 
saprolito espesso e um solo pedológico pouco desenvolvido (neossolos); b. saprolito espesso, recoberto por colúvio que pode atingir até $5 \mathrm{~m}$, pedogeneizado; c. saprolito e solo pedogênico (in situ) espessos; d. saprolito espesso, recoberto por alúvio e/ ou material argilo-orgânico, e/ou colúvio pedogenizado.

Os saprolitos espessos, com neossolos são característicos dos xistos e filitos, podendo ocorrer também sobre os milonitos, em áreas de cisalhamento muito intenso (figura 5) e mesmo próximos aos afloramentos dos granitóides. São também típicos das áreas de topo, alta e meia vertentes, em encostas convexas. Os saprolitos espessos com solos também espessos desenvolvidos in situ, constituem o tipo mais comum encontrado na área de ocorrência das voçorocas. Sobre o saprolito desenvolvem-se latossolos vermelhoamarelo, vermelho-escuro e cambissolos, que tendem a se localizar nos topos próximos aos afloramentos e, em especial, nas baixas vertentes submetidas à erosão basal mais efetiva, como a que ocorre por meandramento (Augustin 1995, Diniz 2002). O último tipo, saprolito espesso recoberto por alúvio e/ou material argilo-

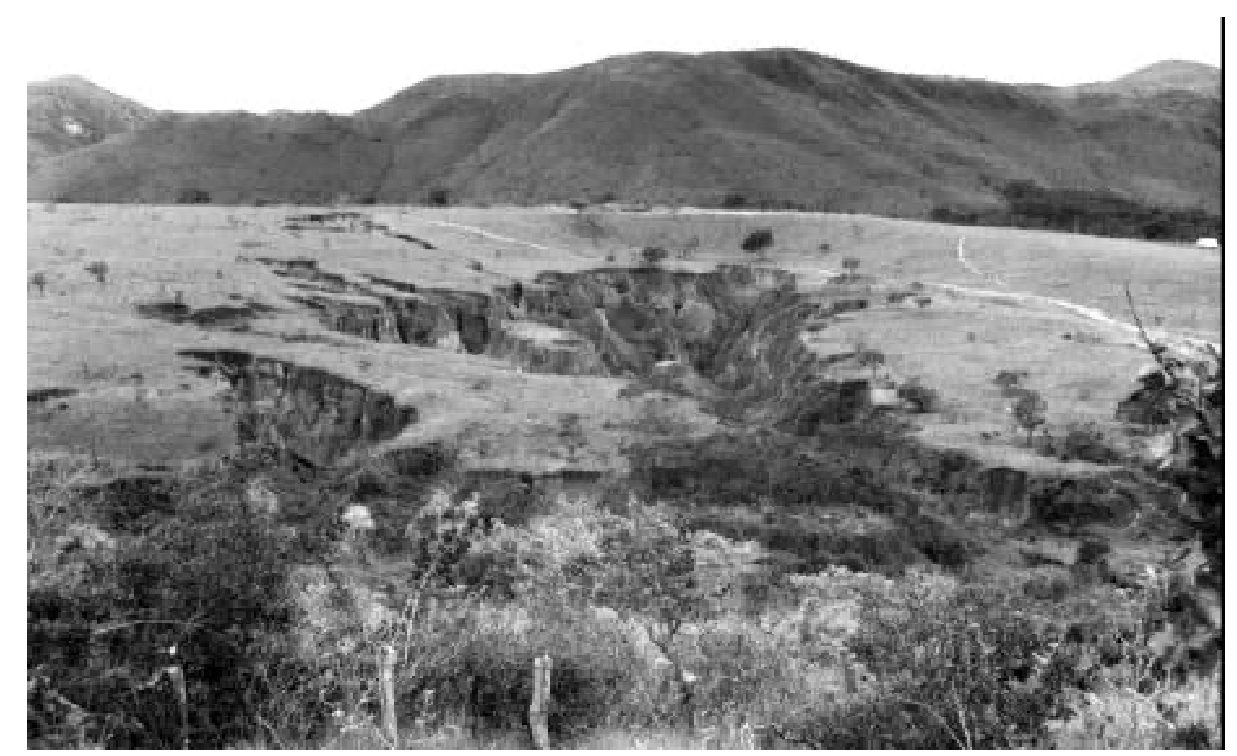

Figura 4-Voçoroca 1, assim denominada por ter sido a primeira estudada de maneira sistemática na área. Ocupa um anfiteatro e tem a ocorrência de piping, responsável pelo desenvolvimento de algumas de suas ramificações. Apresenta saprolito espesso, sobre o qual encontram-se latossolos vermelho-amarelo e vermelho-escuro.

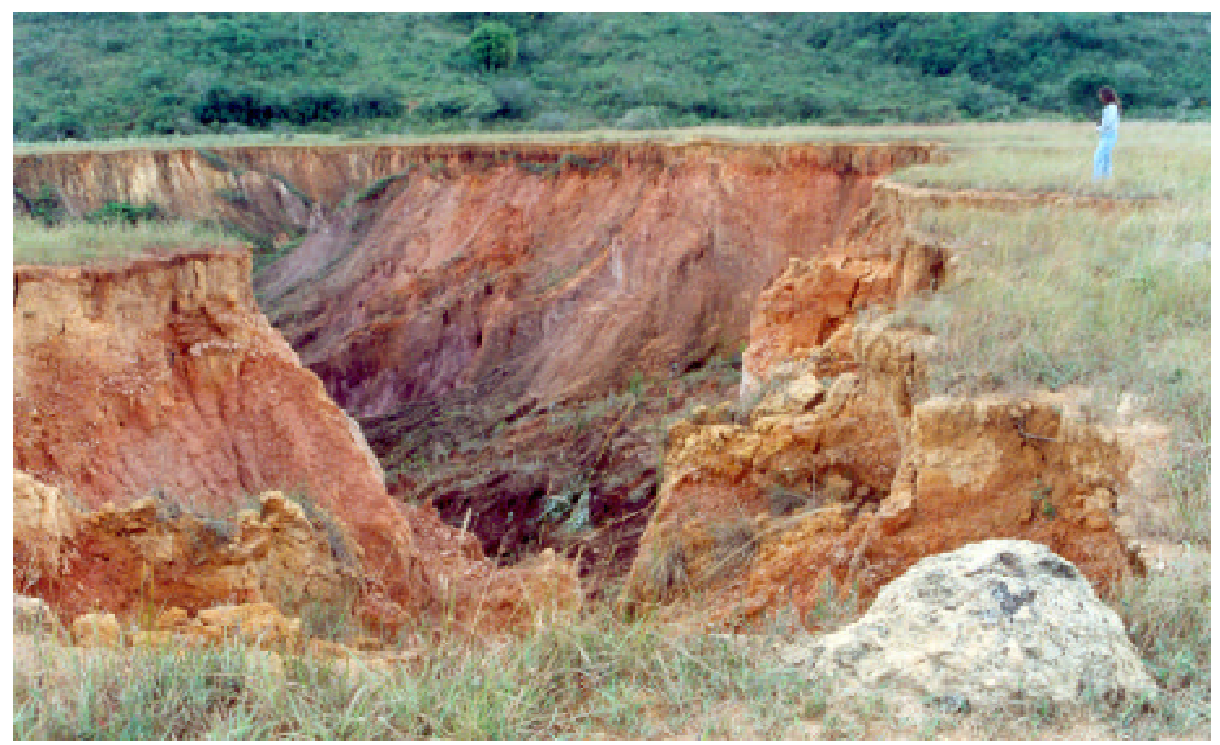

Figura 5-Voçoroca profunda, com cabeceira instável e presença de queda de blocos de rocha intemperizada. Próximo à cabeceira, encontra-se um cupinzeiro, freqüentemente associado ao piping. À direita, dentro da voçoroca, nota-se material residual proveniente da atuação de processos de movimento de massa, acumulado no contato fundo/parede da voçoroca. Enquanto na cabeceira ocorre o contato de um saprolito espesso com latossolo vermelho-amarelo, nas bordas, os solos são rasos. Ao fundo, o canal fluvial do córrego dos Padres, acompanhado por vegetação mais densa que contrasta com a da vertente, onde predomina a gramínea. 
orgânico, e/ou colúvio pedogenizado independe do tipo de rocha, tem sua ocorrência restrita aos sopés das vertentes ou aos anfiteatros, alvéolos de deposição ou a depressões formadas por páleo-voçorocas (Augustin 1995). Sobre esse tipo de saprolito, formam-se neossolos, organossolos solos aluviais e mesmo latossolos vermelho-amarelo e vermelho-escuro, podendo, em condições especiais, ocorrer cambissolos.

Foram encontrados olhos d'água, ou minas de água e fluxo de água contínuo praticamente durante todo o ano, conectando o canal de grande parte das voçorocas mapeadas e estudadas in loco, aos córregos, ribeirões ou rios. Elas apresentam canais bem diferenciados na encosta, podendo ser considerados do tipo contínuo no sentido estabelecido por Leopold et al. (1964) e, portanto, parte do sistema fluvial (Ferreira 1985, Augustin 1995). O voçorocamento, por se constituir um processo que tem especificidades, pode continuar, contudo, a ser classificado como processo de vertente.

O contato entre o canal da voçoroca e o canal fluvial é realizado ao longo de um canal aberto nos sedimentos aluviais e sua forma varia bastante em função da maneira como a voçoroca evoluiu, da sua localização, da declividade da encosta, do encaixamento da drenagem e do tipo de atividade antrópica que causou maior ou menor impacto nos níveis de base locais (Augustin 1995).

No tipo mais comum, o canal da voçoroca intercepta os depósitos provenientes tanto da várzea do canal fluvial, quanto da própria voçoroca. São depósitos intercruzados e intercalados em decorrência dos fluxos de material erodido da voçoroca e do canal fluvial do córrego, ribeirão ou rio (Valadão 1986).

Um outro tipo, encontrado preferencialmente nas voçorocas mais estabilizadas, apresenta um páleocontato, no qual o depósito aluvial estratificado, ou argilo-orgânico, encontra-se recoberto por colúvio. Esse colúvio, depositado sobre o material aluvial-lacustre, retificou a vertente de tal maneira que o contato fica imperceptível na superfície da vertente e somente pode ser detectado por sua exposição pelo voçorocamento, ou com exumação dos antigos terraços pela atividade do garimpo. Em algumas vertentes, é possível ainda identificar de 4 a $5 \mathrm{~m}$ de colúvio nas paredes, sobreposto ao nível do antigo terraço, no qual predomina cascalho com diâmetros variados, mas formado por seixos de quartzo predominantemente arredondados.

Características das Voçorocas Estudadas

As voçorocas estudadas são em geral longas com comprimento médio de $300 \mathrm{~m}$, medidos da cabeceira até a junção com o canal de drenagem. Este comprimento pode, contudo, variar a cada ano, uma vez que, aproximadamente $60 \%$ dessas formas erosivas se encontram ativas. Significa dizer que continuam a apresentar uma erosão a remontante a partir do entalhe da cabeceira (headward erosion), como descrito por De Ploey (1974), Tricart (1966), Moeyersons (1991), Oliveira (1989) entre outros. Esse comprimento médio não reflete a real extensão linear de algumas dessas formas erosivas, que podem atingir mais de $1.000 \mathrm{~m}$, como pode ser observado na foto-área parcial da área (figura 6). A velocidade do crescimento a montante depende de fatores internos ligados à ação do piping, da xistosidade da rocha, maior colapsividade dos solos, mas freqüentemente é influenciada pela ação antrópica: estradas vicinais, remobilização de material próximo à cabeceira, abertura de canaletas para drenagem das estradas e mesmo trilha de gado ou presença de cercas de divisão de propriedades, entre outros. Estudos na área mostram que a cabeceira corresponde ao desenvolvimento linear mais extenso, ou seja ao segmento (ramificação) linear que atinge o ponto mais alto à montante da vertente (figuras 6 e 7).

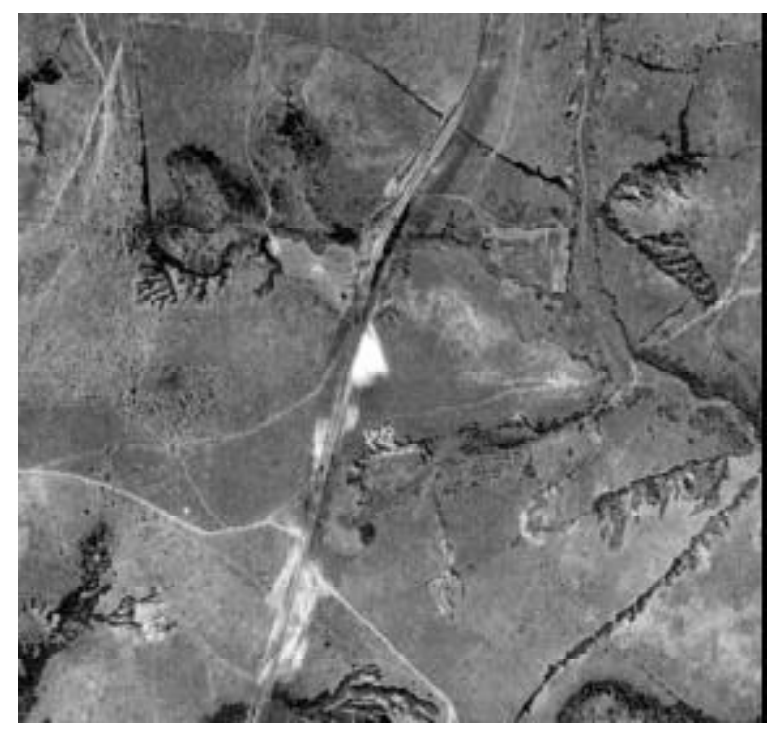

Figura 6- Detalhe de foto aérea de porção da bacia do ribeirão do Chiqueiro, vôo Cruzeiro do Sul (1978), escala 1:28.000. Pode-se identificar voçorocas com formas incongruentes com a direção preferencial do escoamento da água na vertente, típicas das que têm sua gênese associada à ação antrópica, como a abertura de valas $e$ presença de cerca com murundus.

Apresentam larguras variáveis (Malheiros 1985, Ferreira 1985, Augustin 1995, Aranha 2002), dependendo do seu grau de ramificação e, às vezes, ao tipo de ação antrópica que iniciou ou influenciou seu desenvolvimento, associado a fatores naturais como estruturas reliquiares da rocha presentes no saprolito, a ocorrência de páleo-voçorocas e, ainda, a forma da vertente, entre outros. Foram medidas voçorocas com largura média de $13 \mathrm{~m}$ e outras com largura que atingem $150 \mathrm{~m}$. Observou-se que as mais estreitas têm como característica solos pouco desenvolvidos, localizandose sobre rochas que apresentam xistosidade, sejam elas gnaisses, xistos ou milonitos. As mais profundas são típicas das rochas básicas e metabásicas, com a presença de latossolos vermelho-amarelo e vermelhoescuro, tendo sido também detectadas sobre xistos e/ou granito-gnaisses, milonitizados ou não. Ocorrem, 


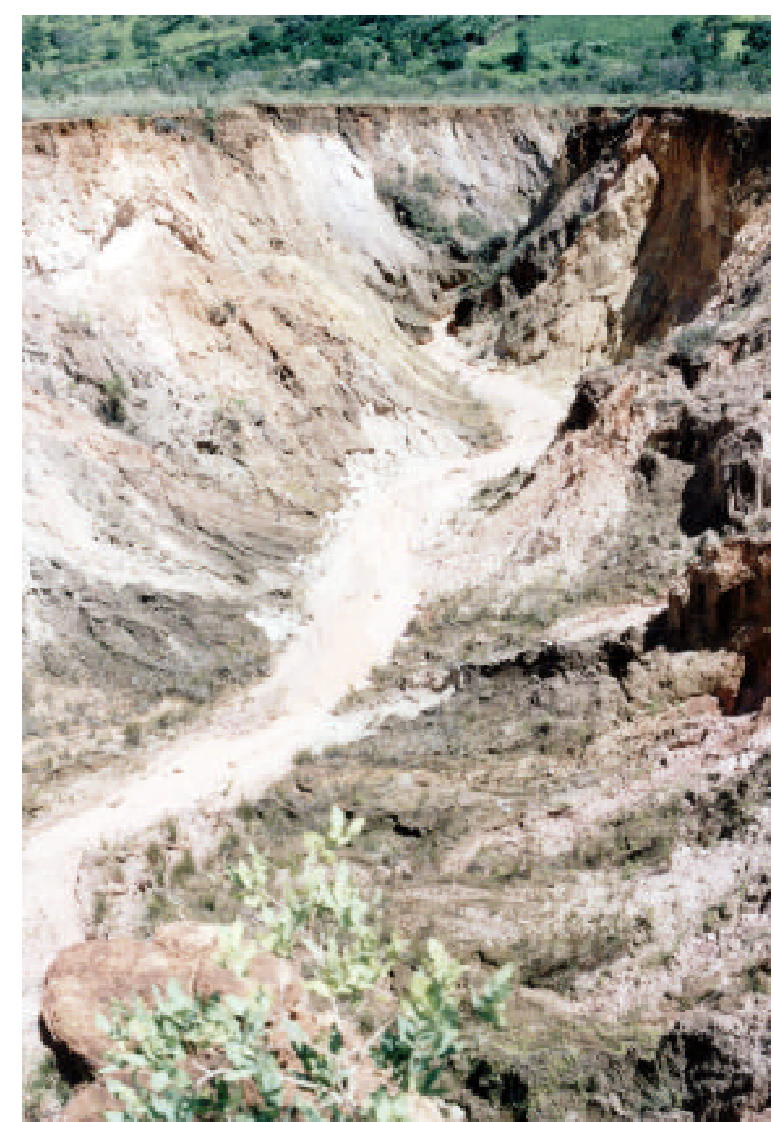

Figura 7- Paredes abruptas, típicas das voçorocas da área, mostrando a direita, na porção inferior da foto, material depositado lateralmente, no contato fundo/parede. O manto é espesso, e sobre ele encontra-se um neossolo. Ao fundo, o córrego dos

Pereiras, ao qual a voçoroca está interligada. em geral, em anfiteatros ou em suas proximidades, ou nas cabeceiras de drenagem (figura 4).

Todas as voçorocas estudadas, com exceções de trechos de algumas delas, apresentam fundo chato, não se encaixando, portanto, na definição proposta por Bull \& Kirkby (1997) que apontam como características típicas de voçorocas o vale em "V". Em Gouveia, os processos responsáveis pela ocorrência de vales em "U", de fundo chato, são os mesmos que respondem pelo alargamento e recuo à montante da cabeceira das voçorocas.

A intensidade da atuação dos processos de erosão e movimentos de massa, que tendem a ocorrer associados, causa um grande acúmulo de material não coeso, ou pouco coeso, entre a parede e o fundo da voçoroca (figuras 5 e 8 ). Parte desse material é transportada pelo fluxo de água, permanente ou não, para os córregos, ribeirões e rios aos quais as voçorocas estão todas conectadas. Outra parte, no entanto, é redistribuída e fica retida no fundo do canal da voçoroca, formando pequenos terraços e, ainda, outra parte, permanece no contato parede/fundo da voçoroca em decorrência da baixa capacidade de remobilização e transporte do fluxo de água. O vale em "U" se forma quando esse material mobilizado não é retirado na mesma velocidade com que é depositado, ficando retido no fundo e nas laterais do canal.

É interessante notar que, quando o movimento de massa, seja ele deslizamento, corrida de lama, ou queda de blocos de rocha intemperizada, causa a deposição de grande quantidade de material entre as paredes e fundo do canal, essa acumulação passa a funcionar como um anteparo ao solapamento basal, além de

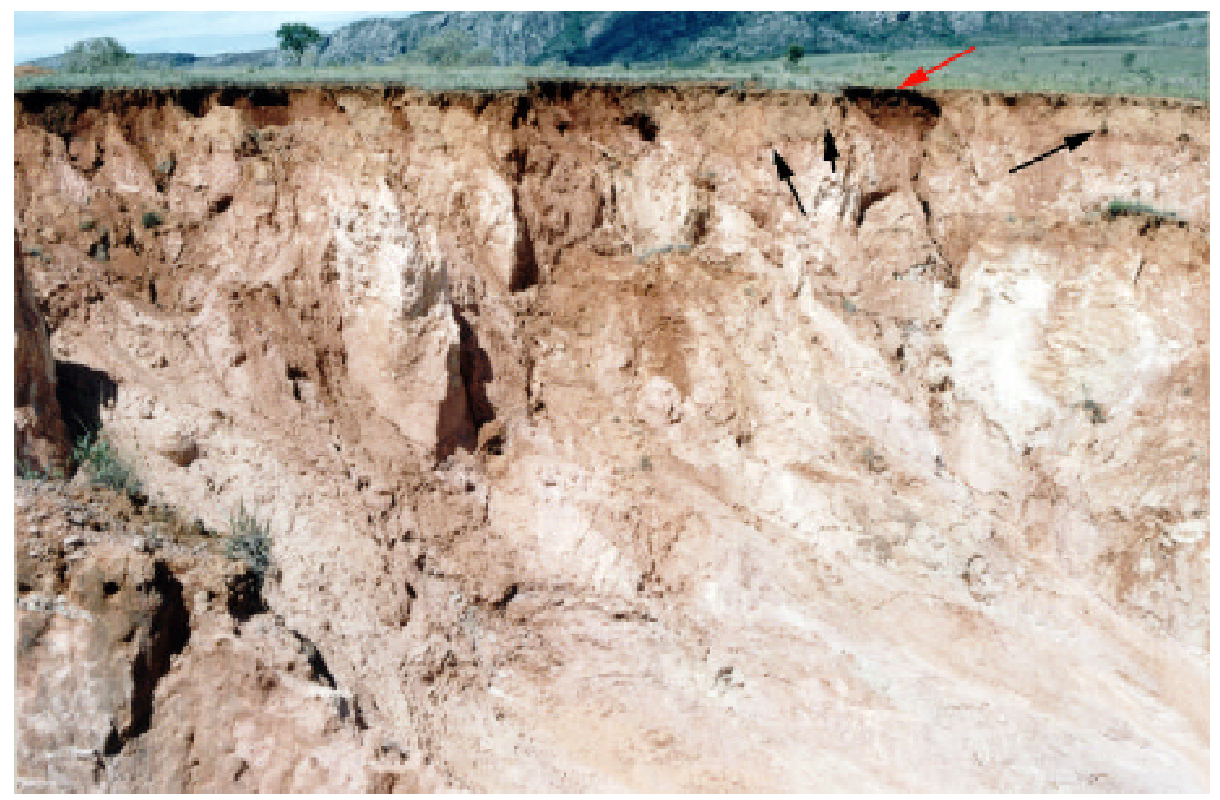

Figura 8- Parede de voçoroca com a ocorrência de dutos de diâmetros variados (indicados pela seta preta), associados com a presença da meso-fauna e de animais roedores. Esses dutos são utilizados para a retirada de sedimentos pelo piping, auxiliando no alargamento das voçorocas. Observa-se também a erosão por alcova, indicada pela seta vermelha. 
calçar a parede, dificultando que esta venha novamente a cair, retardando, assim, o alargamento da voçoroca.

\section{CLASSIFICAÇÃO MORFOLÓGICA DAS VOÇOROCAS}

As formas das voçorocas são variadas e dependem de fatores naturais como tipo de rocha e páleo-relevo, e/ou de fatores antrópicos. Tomando-se como referência a classificação de Ireland et al. (1939), pode-se agrupar as voçorocas de Gouveia quanto a forma em 4 tipos principais: 1) linear, cuja principal característica é o de não apresentar ramificações significativas, sendo formada predominantemente pelo canal principal (figura 9a); 2) dentrítica ou arborescente, que constitui o padrão predominante e se caracteriza por apresentar um padrão de crescimento e desenvolvimento de voçoroca em ramificações (figura 9b); 3) composta, que são aquelas que não apresentam um padrão único, mas podem ser bulbosas e depois lineares, ou vice-e-versa (figura 9c); 4) indefinida, que são voçorocas cujos canais principais estão ainda em processo de abertura não apresentando ainda uma forma definida (figura 9d).

Tanto a largura, quanto a forma e o comprimento das voçorocas em Gouveia, estão associados a múltiplos fatores. Entre estes, destacam-se sua gênese, fatores naturais e fatores antrópicos envolvidos na evolução da forma.

\section{O PROCESSO DE VOÇOROCAMENTO NA ÁREA}

As voçorocas em Gouveia constituem formas ímpares e bem definidas na paisagem, tendo sido responsáveis por intensa perda de solo e impactos importantes na economia da região (Alvarenga 1985, Augustin 1995 e 1999, Aranha 2002). Elas não são confundidas nem com canais de enxurrada e muito menos com ravinas (figuras 4, 5 e 8). O que torna essas formas tão marcantes é, em primeiro lugar, a forma em si, pois ocupa um canal bem definido e delimitado; em segundo, a ocorrência nestes canais, de paredes abruptas, muitas vezes destituídas de cobertura vegetal, que expõe o manto alterado; e em terceiro, o fato de passarem, ou terem passado, por intenso processo de retirada de material do fundo do canal, das suas paredes e da cabeceira (figuras 7 e 8).

A bibliografia relaciona ao tema, associa a formação das voçorocas à abertura de um canal superficial. Contudo, verifica-se que nem todo canal superficial se transforma em voçoroca. O surgimento de um canal superficial ocorre quando a energia cinética da água de escoamento, convertida em mecânica, consegue vencer a resistência das partículas do solo, mobilizando-as e transportando-as ao longo de linhas preferenciais na vertente. O canal superficial também pode, eventualmente, se desenvolver a partir de colapso do
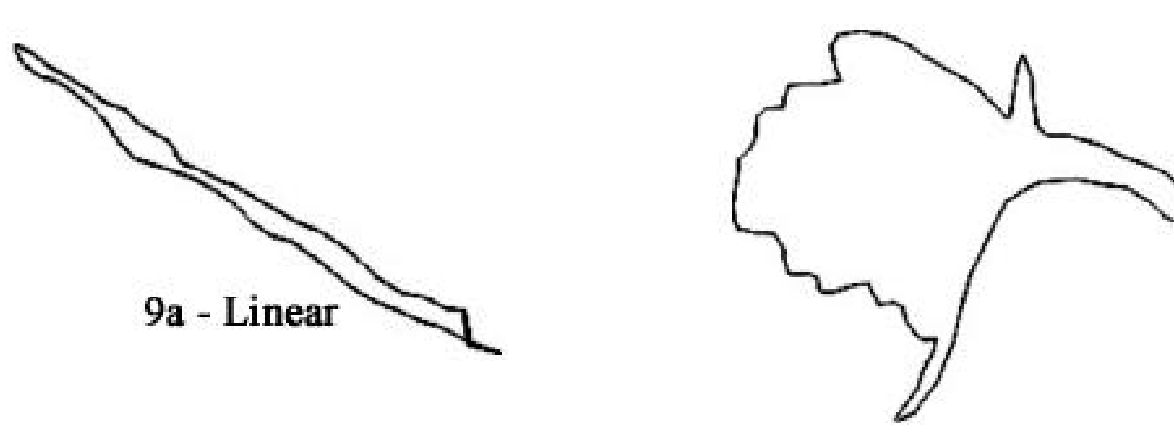

$9 \mathrm{~b}$ - Dendrítica
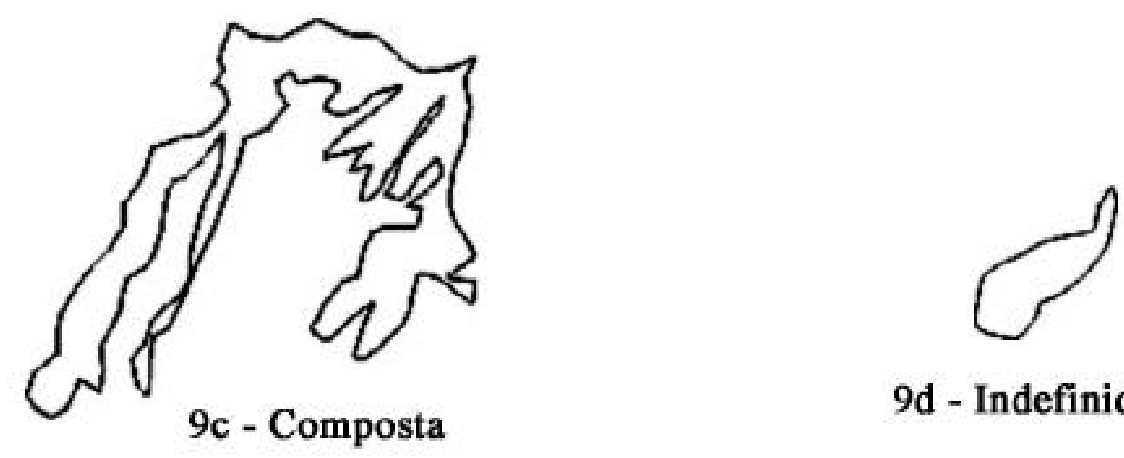

9d - Indefinida

Figura 9- Representação dos 4 tipos predominantes das formas das voçoroca, a partir de mapeamento e foto-interpretação. 
teto de dutos subsuperficiais, formados por piping, como pode ser observado em Gouveia (Aranha et al. 2003).

Vários pesquisadores definem como condição sine qua non para que a forma seja considerada uma voçoroca (Young 1972, Tricart 1973, Food and Agricultural Organization-FAO, In: Bocco 1991), a ocorrência de um canal permanente que não migre a cada período ou evento chuvoso. Esta condição não encontra respaldo nos estudos de Gouveia. O que se constata, na área estudada, é que o aparecimento de um canal superficial profundo o suficiente para concentrar o escoamento superficial da água de chuva, chuva após chuva, e período chuvoso após período chuvoso, pode continuar a evoluir como um canal, como é o caso das ravinas. Portanto, o desenvolvimento de um canal superficial permanente de enxurrada, deve ser considerado apenas como um estágio inicial favorável ao desenvolvimento de uma voçoroca.

Para que o canal evolua para voçoroca, é necessário, além da atuação da erosão, a presença de um conjunto de processos, entre os quais os movimentos de massa e o piping, que desestabilizam as paredes e a cabeceira do canal, provocam seu alargamento e sua evolução à montante, caracterizando uma voçoroca (figuras 8). Eventualmente, com o aprofundamento do canal, estes interceptam o nível freático, tornando quase permanente o fluxo de água, o que tende a acelerar ainda mais a erosão e a atuação dos processos de movimento de massa.

Estudos realizados na área indicam que a água de escoamento inicia seu trabalho de retirada e transporte de material, antes mesmo de atingir as bordas das voçorocas, carreando material de fora para dentro, em especial nas localizadas nos anfiteatros, alvéolos ou depressões. Após atingir as bordas, o poder erosivo do escoamento, aumentado pelo material mais grosso em transporte, causa a retirada do solo nas paredes e cabeceira. O efeito da enxurrada na cabeceira provoca em alguns casos, o aparecimento do que Oliveira (1989) denominou de alcova, ou seja, bolsões suspensos, do tipo marmita, que se formam pela diferença de resistência do material à força erosiva da enxurrada, o que impede uma retirada contínua do material ao longo da parede (figura 8).

Em eventos chuvosos com alta precipitação, a capacidade erosiva da água acumulada no fundo do canal da voçoroca é muito grande, causando freqüentemente o solapamento basal das paredes, desencadeando processos de transferência gravitacional, como os deslizamentos (figura 6). Eles são mais freqüentes durante o período de verão, quando há a precipitação da maior parte dos $1.500 \mathrm{~mm}$ de pluviosidade média anual da área.

Além dos deslizamentos e da erosão, a ocorrência de corridas de lama também contribui para o alargamento, o recuo das cabeceiras e o acúmulo de material no fundo das voçorocas (figura 7). As corridas de lama são mais comuns após um período prolongado de chuva, ou no final da estação chuvosa, em voçorocas mais profundas que já interceptaram o nível freático, pois este se encontra saturado e elevado. Quando o material basal atinge o limite de liquidez, ele escoa, causando uma corrida de lama que, em geral, inicia também o deslizamento, ou corrida da terra mais seca da porção superior da parede afetada pela corrida de lama. O material que entra em colapso apresenta feição caótica, no qual se identificam blocos mais inteiros, provenientes do deslizamento e da queda da rocha intemperizada, misturados ao material totalmente disforme, resultante do escorrimento da corrida de lama.

Outro processo de movimento de massa observado na área, e mais comumente encontrado nas cabeceiras, é a queda de blocos de rocha alterada. A principal diferença entre esse processo e o deslizamento é que na queda de blocos, não há formação da superfície de cisalhamento; os blocos caem por ação da gravidade e pelo aumento da tensão interna do material das paredes das cabeceiras, cujas bases colapsam por perda de coesão, sem que tenha se desenvolvido uma superfície de deslize.

Também foi detectada a ação de piping na base do canal, junto ao nível freático, como reportado por Bigarella \& Mazuchowski (1985). Esses pipings causam escavações "em conchas", que evoluem até a retirada do apoio basal da parede, levando ao seu colapso e ao alargamento da voçoroca. Além do piping basal, observa-se ao longo das paredes, a presença de dutos de diversos diâmetros formados pelo piping, associado às atividade biótica da meso-fauna e de roedores, bem como à percolação de água sub-superficial em linhas preferenciais (figura 8). Estes também contribuem para a desestabilização das paredes das voçorocas através do aumento dos canais dos dutos. Eventualmente o teto desses dutos colapsa, criando canais superficiais, que evoluem como ramificações das voçorocas (figura 4). Os pipings não basais também estão associados além do carreamento de partículas, ao aumento do conteúdo de água escoando pelas paredes, criando condições para o aparecimento de deslizamentos e corridas de lama (figura 5).

\section{GÊNESE DAS VOÇOROCAS}

\section{Fatores Antrópicos}

A gênese e a localização das voçorocas encontramse associadas a fatores antrópicos e à ocorrência de páleo-relevos, que criam as condições básicas para que ocorra um desequilíbrio entre a quantidade e a velocidade da água de chuva (potencial erosivo), e a quantidade de material efetivamente mobilizado dentro do canal. Entre as ações antrópicas mais importantes atuando na área estão: a) o desmatamento e as queimadas periódicas que a área é submetida; b) a abertura de valas e uso de tipo específico de cerca com murunduns para separação de propriedades (Alvarenga 1985, Augustin 1995); d) o pisoteio do gado e a presença de trilhas e) a abertura e drenagem de estradas vicinais (Augustin 1995); f) o plantio em linha; g) as atividades 
de mineração (Augustin 1995). Desses fatores somente será discutido o impacto das cercas, pois os demais tipos de fatores são mais comumente encontrados em outras áreas com voçorocamento.

Foram identificados 3 tipos predominantes de cercas na área:

1. muros de pedras que permanecem até hoje dividindo propriedades. Esse tipo, ao contrário dos demais, funciona como obstáculo à ação erosiva da água de escoamento superficial da chuva, quebrando a velocidade da água de escoamento e dispersando-a. Mesmo em situações nas quais o muro foi construído acompanhando a linha de máxima declividade da vertente, não houve o desenvolvimento de voçorocas;

2. valas construídas para separar propriedades ou porções de uma mesma propriedade. Essas valas foram abertas possivelmente durante uma época de difícil aquisição de arame farpado e se transformaram em voçorocas, distribuídas por todo o município. A abertura de valas relativamente profundas, serviu de elemento catalizador para a atuação da água concentrada que aprofundou o canal, acompanhada da ocorrência de movimentos de massa, que alargaram suas bordas e fizeram recuar a cabeceira, provocando a instabilidade de toda o canal. Normalmente é fácil identificar as voçorocas que tiveram essa gênese, porque apresentam formas incongruentes com o escoamento natural da água de chuva, apresentando canais que cortam perpendicularmente a vertente, ou então formando um semicírculo no encontro da depressão do anfiteatro ou alvéolo com a encosta (figura 6). Esse semicírculo se conecta a várias ramificações que se desenvolvem vertente acima, como pode ser observada na Figura 4. As valas que deram origem aos semi-círculos, foram escavadas para drenar a água de escoamento superficial das poucas áreas cultiváveis, localizadas nos anfiteatros, alvéolos e depressões;

3. cercas com 2 ou 3 linhas de arame farpado, que cortam todo o município. Trata-se de cerca comum, de arame farpado, que em vez de 4 ou 5 fios de arame, contam com apenas 2 ou 3. Para fechar a cerca na sua parte inferior, já que os fios de arame somente conseguem proteger a parte superior, foram construídos pequenos murunduns de terra, que ladeiam a cerca ao longo de toda sua extensão. Esses murunduns têm o efeito de canalizar a água de escoamento da chuva, tornado-se canais naturais, que tendem a se aprofundar e alargar, abrindo-se em voçorocas. Fatores naturais intensificam esse efeito, como quando o canal formado intercepta dutos formados por piping, zonas preferenciais de escoamento sub-superficiais, ou solos muito colapsíveis, como os latossolos vermelho-escuro, formados sobre rochas básicas e metabásicas. Como no caso das valas, a orientação do escoamento superficial pelo murundum, cria voçorocas com formatos que nem sempre estão de acordo com a direção de escoamento natural da água na vertente (figura 6).

\section{FATORESGEOMORFOLÓGICOS}

Algumas voçorocas foram abertas e evoluíram em canais de antigas voçorocas datadas do PleistocenoHoloceno. As idades do material argilo-orgânico, depositado e exumado pelas voçorocas atuais, variam de $38.750 \pm 5.100 / 3.100$ e $20.940 \pm 715 \mathrm{yr}$ BP, datado por meio de $C^{14}$ (Augustin 1995), indicam a atuação de processos de voçorocamento pretéritos, sugerindo que se trata de um fenômeno policíclico. O mesmo foi reportado por Bigarella e Mazuchowski (1985), para os quais as voçorocas representam a alternância de sucessivos ravinamentos, com períodos de preenchimento desses canais. Neste sentido, pode-se considerar que essas formas erosivas ocorrem sem a interferência do homem, constituindo, na verdade, como defendido por Rougerie (1966:p.27), um fenômeno que representa "a maneira normal de modelagem das vertentes, nas condições atualmente realizadas". Significa dizer, que, em alguns casos, a ação antrópica, constitui apenas um elemento facilitador.

\section{CONCLUSÃO}

A ocorrência de voçorocas está predominantemente restrita ao domínio das rochas granito-gnáissicas, miloníticas, filíticas, básicas e metabásicas, que formam o subtrato rochoso da depressão de Gouveia. As voçorocas são feições distintas na paisagem não se confundindo com ravinas. O canal se forma através da erosão provocada pela água de escoamento superficial da chuva, ou pelo colapso do teto de dutos formados por piping.

A evolução ocorre pela atuação do voçorocamento, um processo complexo, que associa a atuação de processos erosivos superficiais e subsuperficiais como os de movimentos de massa, em especial o deslizamento, corrida de lama e queda de blocos de rochas altamente intemperizada. A intensa incisão do canal, acompanhada do seu alargamento e do recuo da cabeceira, é consequiência direta do desequilíbrio que se instala no interior do canal, impedindo sua colonização pela vegetação.

Há um número grande de voçorocas que se desenvolveram nos últimos 150 anos, após grande desmatamento para o uso e ocupação dos solos com atividades agropecuárias. Além do desmatamento, que favorece a concentração da água de chuva em enxurradas, a abertura de valas para separar propriedades, o tipo de cerca utilizada na região, as atividades de mineração, bem como a drenagem das estradas vicinais, estão entre as principais causas de origem antrópica para o voçorocamento na região.

Contudo, há outros fatores, intrínsicos às característica biofísicas da áreas, como ocorrência de solos muito colapsíveis, intensa atividade biológica , tais como térmitas, formigas e roedores e a ocorrência 
de um páleo-relevo, que têm influência e podem iniciar o processo. Evidências de campo e laboratório, comprovam que algumas voçorocas são policíclicas, com a re-incisão de páleo-canais formados por voçorocamentos ocorridos no Pleistoceno-Holoceno. $\mathrm{O}$ grande número de estudos conduzidos na área permitiu que, além de um melhor entendimento do processo, se tivesse também um panorama mais claro das características das voçorocas e do impacto das mesmas no município de Gouveia.

Agradecimentos: À Fundação de Amparo à Pesquisa do Estado de Minas Gerais (FAPEMIG), pelo apoio financeiro às pesquisas (CEX: 1699/95 e CRA: 957/01) que deram suporte a essa publicação.

\section{REFERÊNCIAS}

Alvarenga A.F.B. 1985. Uso e Ocupação do Solo na Porção Norte Ocidental da Cidade de Gouveia - MG. Monografia de Graduação, Departamento de Geografia, Instituto de Geociências, Universidade Federal de Minas Gerais. Belo Horizonte, MG. 61p.

Aranha P.R.A. 2002. Estudo das Coberturas Superficiais e sua Dinâmica na Região de Gouveia, Serra do Espinhaço, MG: Utilizando o Radar de Penetração no Solo (GPR). Tese de doutorado, Departamento de Geologia da Escola de Minas, Universidade Federal de Ouro Preto, MG. 305p.

Aranha P.R.A., Augustin C.H.R.R, Duarte L.M., Timbó E. 2001. A ocorrência de pipes descontínuos em Gouveia, MG, Brasil, detectado com o auxílio do Ground Penetrating Radar (GPR). In: XI Congresso Latino Americano de Geologia, Montividéu, Uruguai, Anais... Cdrom no 275 (pdf).

Aranha P.R.A., Augustin C.H.R.R., Sobreira F.G. 2002. The use of GPR for characterizing underground weathered profiles in the sub-humid tropics. Journal of Applied Geophysics, 49: $195-210$.

Augustin C.H.R.R. 1995. Geoökologishe Studien im südlichen Espinhaçogebirge bei Gouveia, Brasilien unter besonderer Berücksichtingung der Landschaftsentwicklung. Tese de doutorado, Johann Wolfgang Goethe Universität, Frankfurt, Alemanha, 150p.

Augustin C.H.R.R., Aranha P.R.A., Pires Fo. J.L. et al. 1999. Relatório Técnico-científico Final: Estudo das Coberturas Superficiais e sua Dinâmica Cenozóica na Região de Gouveia, Espinhaço Meridional. Projeto de Pesquisa, CEX 1669-96, Belo Horizonte, MG. 526p.

Augustin C.H.R.R., Aranha P.R.A., Pires Po. J.L. et al. 2005. Relatório Técnico-científico Final: Dinâmica Ambiental em Trópico Úmido, Espinhaço Meridional, MG. Projeto de Pesquisa, CRA 975/01, FAPEMIG. Belo Horizonte, MG, $362 \mathrm{p}$.

Augustin C.H.R.R., Saadi A. 1985. Degradação Ambiental: Estudo Comparativo entre uma Área Rural (Gouveia-MG) e uma Urbana (NW de Belo Horizonte). Projeto de Pesquisa submetido ao Departamento de Geografia, IGC, UFMG. Belo Horizonte, MG. 22p. (Inédito)

Bigarella J.J., Mazuchowski J.Z. 1985. Visão Integrada da Problemática da Erosão - 30o Simpósio Nacional de Controle da Erosão, ABGE, ADEA, Maringá, PR, 332p.

Bocco G. 1991. Gully Erosion: Processes and Models. Progress in Physical Geography, 15:392-406.

Bull L.J. \& Kirkby M.J. 1997. Gully processes and modelling. Progress in Physical Geography, 21:354-374.

Casali J., Loiuzu J., Campo M.A., De Santisteban L.M., ÁlvaresMozos J. 2006. Accuracy of methods for field assessment of rill and ephemeral gully erosion. Catena, 67:128-138.

Casali J. Lopez J.J., Giraldez J.V. 1999. Ephemeral Gully Erosion in
Southern Navarra (Spain). Catena, 36:65-84.

Coelho Neto A.L., Fernandes N.F, Deus C.E. 1988. Gullying in southeastern Brazilian Plateau, Bananal, SP. In: IAHS, Proceedings of the Porto Alegre Sumposium of Sediments Budgets, 174:35-42.

Crouch R.J. 1990. Erosion Processes and Rates for Gullies in granitic soils Bathurst, New South Wales, Australia. Earth Surface Processes and Landforms, 15:169-173.

Crouch R.J., Blong R.S. 1989. Gully, sidewall classification: methods and applications. Zeitchrift für Geomorphologie, 33:291-305.

De Ploey J. 1974. Mechanical properties of hillslopes and their relation to gullying in Central semi arid Tunesia. Zeitschrift für Geomorphologie, Suppl-Bd., 21:177-190.

Diniz A.D. 2002. Levantamento Pedológico da Porção Norte da Bacia do Ribeirão do Chiqueiro e a Relação entre Classes de Solo e a Erosão, Gouveia, MG. Dissertação de Mestrado, Instituto de Geociências, Universidade Federal de Minas Gerais. Belo Horizonte, MG, 127p.

Ferreira M.B. 1985. Análise Morfométrica das Redes de Drenagem de Voçorocas do Alto Paraúna (Gouveia) - Serra do Espinhaço, MG, Etapa Preliminar. Monografia de Graduação. Departamento de Geografia, Instituto de Geociências, Universidade Federal de Minas Gerais, Belo Horizonte, MG, $76 \mathrm{p}$.

Fiori L. \& Soares A. 1976. Aspectos relativos das voçorocas. Notícias Geomorfológicas, Campinas, 32:40-48.

Fogaça C., Schöll W.U. 1979. Estratigrafia da Serra do Espinhaço na Região de Diamantina (MG). In: SBG, Simpósio de Geologia de Minas Gerais, Diamantina, MG, Anais... pp. 5571.

Furlani G.M. 1980. Estudo geomorfológico das boçorocas de Casa Branca - São Paulo. Dissertação de Mestrado, Departamento de Geografia, FFLCH - USP, São Paulo, 379p.

Heede B.H. 1967. Morphology of gully in the Colorado Rocky Mountains. Bull Inst. Assoc. Sci. Hydr., XV:78-89.

Ireland H.A., Sharpe C.F., Eargle D.H. 1939. Principles of gully erosion in the piemont of South Carolina. US Department of Agriculture, Technical Bulletin, Washington DC, 633p.

Iwasa O.Y. \& Prandini F.L. 1980. Diagnóstico da origem e evolução de boçorocas: condição fundamental para prevenção e correção. In: ABGE, Simpósio sobre o controle de erosão, Curitiba, Anais... São Paulo, Vol II, pp. 5-34.

Jones J.A.A. 1971. Soil Piping and Stream Channel Iniciation. Water Resources Research, 3:602-610.

Kirkby M.J. 1978. Hidrolog;y slope (Physical geography). Ed. Wiley, New York, EUA, 389p.

Leopold L., Wolman M., Miller J. 1964. Fluvial Processes in Geomorphology. W.H. Freeman and Company (Eds). São Francisco, EUA, 522p.

Malheiros D.D. 1986. Análise Preliminar da Morfologia das Bordas das Voçorocas da Região do Alto Paraúna, Serra do Espinhaço-Gouveia-MG-/2 a Etapa. Monografia de Graduação, Departamento de Geografia, Instituto de Geociências, Universidade Federal de Minas Gerais. Belo Horizonte, MG, 153p.

Moeyersons T. 1991. Ravine formation on steep slope: forwards versus regressive erosion- some study cases from Rwuanda. Catena, 10:308-321.

Oliveira M.A.T. 1989. Erosion disconformities and gully morphology: a three dimensional approach. Catena, 16:413423.

Petit M. \& Bourgeat F. 1966. Os Lavaka Malgaches: Um Agente natural de Evolução das Vertentes. Boletim Geográfico, Ano XXV, Rio de Janeiro, 190:29-32.

Pichler E. 1953. Boçorocas. Boletim da Sociedade Brasileira de Geologia, 1:3-16.

Poesen J., Govers G. 1990. Gully erosion in the loam belt of Belgium:typology and control measures. In: Boardman J., Foster D.L., Dearing J.A. (eds.), Soil Erosion on Agricultural Land, Wisley, UK, pp. 513-530.

1993. Gully tipology and gully control measures in European loess belt. In: Wicherek, S. (ed.) Farm, Land Erosion in Temperate Plains Environment and Hills, Elsevier, 
Amsterdam, pp. 221-239

Poesen J., Vandaele K., Wasemael Van B. 1998. Gully erosion: importance and model implications. In: Boardman J., FavisMortlock D.T. (eds) Modelling Soil Erosion by Water, NATO-ASI Series, Springer-Verlag, Berlim, 1-55:285-331.

Rodrigues J.E. \& Vilar O.M. 1984a. Estudo da Erosão Interna em Voçorocas através da Teoria do Carreamento. In: ABGE, 40 Congresso Brasileiro de Geologia de Engenharia, Belo Horizonte, MG, Anais..., 2, pp. 163-168.

1984b. Estudo Geotécnico de Fenômenos Erosivos Acelerados (Boçorocas). In: ABGE, 40o Congresso Brasileiro de Geologia de Engenharia, Belo Horizonte, MG, Anais..., 2, pp. 169-182.

Rougerie M.G. 1966. Os Lavaka na Evolução das Vertentes em Madagáscar. Boletim Geográfico, Ano XXV, Rio de Janeiro, 190: $18-28$.

Saadi A. \& Valadão R.C. 1987. O cenozóico da porção medianacentral do Espinhaço Meridional. In: Abequa, $\mathrm{I}^{\circ}$ Congresso da Assoçiação Brasileira de Estudos do Quaternário, Porto Alegre,
RS, 1a. síntese, pp. 398-407.

Tricart J. 1953. Erosion naturelle et erosion anthropogène à Madagascar. Rev. Géomorphol. Dynamique, 5:225-230.

1966. As descontinuidades nos fenômenos da erosão. Notas Geomorfológicas, Campinas, 12:3-14.

Valadão R.C. 1986. Estudo sedimentológico das formações superficiais do "Sistema Alveolar do Córrego dos Pereiras" (Ribeirão do Chiqueiro-Espinhaço Meridional-MG). Monografia de Graduação, Departamento de Geografia, Instituto de Geociências, Universidade Federal de minas Gerais. Belo Horizonte, MG. 78p.

Valentin C., Poesen J., Yong Li 2005. Gully erosion: Impacts, factors and control. Catena, 2-3:132-153.

Vieira N.M. 1978. Estudo Geomorfológico das Voçorocas de Franca (SP). Tese de doutorado, Faculdade de Filosofia, Ciências e Letras de Franca, SP, 225p.

Young A. 1972. Slopes. Logman (Ed). Londres, 160p 